\title{
National Cancer Policy Board
}

National Cancer Institute

\section{Source}

National Cancer Institute. National Cancer Policy Board. NCI Thesaurus. Code C19140.

The NCPB is intended to confront obstacles and address issues that arise in the prevention, control, diagnosis, and treatment of cancer. It meets at least three times annually to examine ongoing research, new technologies, issues arising in delivery of care, and problems faced in the Nation's battle against cancer. It serves as a common meeting ground for the many federal agencies that sponsor or directly conduct relevant work as well as state and local health authorities. The Board's most distinctive contribution, however, will be to render advice to the Nation in the area of policy and make recommendations to advance the Nation's effort against cancer. 